\title{
La promoción de símbolos identitarios en tiempos de «crisis»: el caso de las ciudades y villas catalanas entre mediados del siglo XIV y finales del siglo $\mathrm{XV}^{*}$
}

\author{
Albert Reixach Sala ${ }^{1}$ \\ Universitat de Girona \\ albert.reixach@udg.edu
}

RESUMEN: El presente artículo analiza la promoción de elementos identitarios por parte de los gobiernos municipales catalanes desde mediados del siglo XIV hasta finales de la centuria siguiente, periodo que la historiografía habia tendido a considerar de recesión. A partir de la combinación de datos inéditos e información bibliográfica de procedencia diversa, se presta atención a iniciativas orientadas a fortalecer la imagen externa de las corporaciones locales durante la cronología apuntada: la construcción y progresiva decoración de las casas consistoriales de las principales poblaciones, la adquisición de mobiliario y la creciente preocupación por la apariencia y la indumentaria de los magistrados municipales. Todo este proceso se vincula con el grado de madurez institucional alcanzado por los entes locales desde finales del trescientos y se pone en relación con otros territorios europeos. Nos obliga, en última instancia, a plantear nuevas perspectivas de interpretación de la idea tradicional de crisis de las corporaciones municipales en la Cataluña de los siglos XIV y XV.

* El presente trabajo se ha elaborado en el marco del proyecto «La coyuntura económica y demográfica en Cataluña a fines de la época medieval: análisis crítico de los indicadores fiscales y financieros» (HAR2014-54205-C2-1-P) y del grupo de investigación consolidado de la Generalitat de Cataluña «Renda feudal i fiscalitat a la Catalunya baixmedieval» (2017 SGR 1068).

Abreviaturas utilizadas: ACCE, Arxiu Comarcal de la Cerdanya, Puigcerdà, Gerona; AMGi, Arxiu Municipal de Girona, Gerona; MdA, Manuals d'acords; AHCB, Arxiu Històric de la Ciutat de Barcelona, Barcelona; ACGAX, Arxiu Comarcal de la Garrotxa, Olot, Gerona; AHG, Arxiu Històric de Girona, Gerona.

${ }^{1}$ ORCID iD: https://orcid.org/0000-0002-4364-4901.

Copyright: (C) 2020 CSIC. Este es un artículo de acceso abierto distribuido bajo los términos de una licencia de uso y distribución Creative Commons Reconocimiento 4.0 Internacional (CC-BY 4.0) 


\title{
Palabras Clave: Cataluña; baja Edad Media; crisis; municipio; casa consistorial; identidad política.
}

\section{Promoting identity symbols in times of "crisis": Catalan towns and cities between the mid-fourteenth and late fifteenth centuries}

\begin{abstract}
This essay deals with the promotion of identity elements by municipal governments in Catalonia from the mid-fourteenth to the end of the following century, traditionally considered a period of recession in scholarly literature. A combination of hitherto unpublished data and bibliographical information from different sources enable a focus on initiatives aimed at reinforcing the external image of local corporations at this time: the building and progressive embellishment of town halls in major municipalities, the purchasing of furniture and a growing concern for the appearance and clothing of the municipal magistrates. This process is connected with the degree of institutional maturity reached by local entities as of the end of the fourteenth century and can be compared to other European territories. Finally, the article suggests new perspectives on the traditional idea of crisis in Catalan municipalities throughout the fourteenth and fifteenth centuries.
\end{abstract}

KeY WORD: Catalonia; Late Middle Ages; crisis; municipality; town hall; political identity.

CÓMO CITAR ESTE ARTÍCULO/CITATION: Reixach Sala, Albert, «La promoción de símbolos identitarios en tiempos de "crisis": el caso de las ciudades y villas catalanas entre mediados del siglo XIV y finales del siglo XV», Hispania, 80/265 (Madrid, 2020): 343-372. https://doi.org/10.3989/hispania.2020.009

A comienzos del año 1424, el orden del día de una sesión del consejo municipal de Gerona, que se celebraba en la casa consistorial inaugurada hacía una década, incluía varios puntos. De entrada, los presentes debatieron sobre posibles medidas para hacer frente al elevado endeudamiento de la tesorería local. Asimismo, nombraron procuradores para llevar a cabo las acciones legales iniciadas contra contribuyentes y recaudadores que no habían cumplido con sus obligaciones, y que impedían abordar con garantías el proyecto de saneamiento deseado. No obstante, a pesar de los problemas que padecían las arcas de la institución, nadie se opuso a otro acuerdo: duplicar el salario anual (de 10 a 20 sueldos barceloneses) percibido por los miembros del ejecutivo local. El aumento se justificó por el mero hecho de que, atendiendo al honor del oficio, debían renovar por completo su indumentaria, puesto que los ropajes que hasta entonces lucían no eran lo suficientemente uniformes al incorporar forros de distintos tipos de piel $^{2}$. Ante la paradoja podríamos preguntarnos si se trataba

\footnotetext{
2 AMGi, MdA año 1424, ff. 6v-9r, 1424/01/01.
} 
de medidas contradictorias o, en cambio, nos encontramos ante actuaciones para nada incompatibles.

A la luz de esta cuestión, el presente artículo busca analizar la inversión en símbolos comunitarios en la Cataluña de la Baja Edad Media, un periodo que tradicionalmente se ha considerado de recesión económica. No en vano, entre las últimas décadas del trescientos y mediados del cuatrocientos, fueron muchos los gobiernos municipales que hicieron esfuerzos para construir edificios propios del concejo y dotarlos de mobiliario y decoración, a la par que aumentaron el gasto destinado a la indumentaria de sus representantes y a otros emblemas corporativos. De hecho, se trata de una dinámica detectada a lo largo y ancho de la Europa bajomedieval en la que se consolidó una verdadera polisemia de poderes ${ }^{3}$. Aunque con cronologías variables entre los siglos XIII y $\mathrm{XV}$ y bajo circunstancias históricas distintas, las comunidades urbanas de áreas como la Península Itálica, los antiguos Países Bajos, el Mediodía francés, el Imperio Germánico o la Península Ibérica afirmaron su identidad frente a instancias de poder superior, y lo hicieron visible a través de discursos y manifestaciones diversas, ya fueran en el ámbito artístico, de las ceremonias y rituales, o mediante otros mecanismos de autorepresentación ${ }^{4}$.

En el caso de la Corona de Aragón, en general, y de Cataluña, en particular, durante los últimos años se ha prestado cierta atención a algunos de estos mecanismos ${ }^{5}$. Sin embargo, hasta el momento, la perspectiva de las manifestaciones arquitectónicas y artísticas no se ha acabado de incorporar al análisis del desarrollo de las instituciones locales durante el periodo bajomedieval. De hecho, no han arraigado las líneas de investigación sobre edilicia y poderes políticos habituales en otras áreas ${ }^{6}$. En consecuencia, los trabajos sobre edificios de uso comunitario y otros elementos concomitantes constituyen un conjunto bastante disperso. Como han señalado autores de referencia, un primer motivo de ello podría ser que el tema se encuentra en una auténtica encrucijada entre disciplinas, o sea, a medio camino entre la historia urbana y política y la historia de la arquitectura y del arte, por lo que los respectivos especialistas sólo han demostrado un interés parcial por la cuestión? ${ }^{7}$. Cierto

${ }^{3}$ WATTS, 2009: 98-116, en relación con las corporaciones municipales.

${ }^{4}$ Sólo a modo de ejemplo: LECUPPRE-DESJARDIN, 2004: 49-102, 127-130, 246-258, 318-322. LECUPPRE-DESJARDIN y CROUZET-PAVAN, 2008. GILLI y SALVATORI, 2014. MONNET, 2004. JARA FUENTE, 2013.

5 VERDÉS, 2011. SABATÉ, 2013.

${ }^{6}$ GROHMANN, 2005. Así, a pesar de las investigaciones dedicadas a la historia de la construcción, sobre todo desde el punto de vista de la historia social y, como veremos, del arte, sólo algunos trabajos se han adentrado en su dimensión política: CUBELES, 2001. NAVARRO, 2005. SERRA DESFILIS, 2010. Puede compararse con el caso de Castilla: BONACHÍA, 2013.

7 CHEVALIER, 2005: 15-18. 
es que gracias a la historia del arte contamos con algunos estudios dedicados a identificar y describir construcciones de titularidad pública de la Baja Edad Media $^{8}$. Pero, salvo pocas excepciones, como una monografía dedicada a Tortosa, se trata de estados de la cuestión alimentados en muchas ocasiones por bibliografía escasamente respaldada en investigación de archivo o que, ante la ausencia de perspectiva comparada, no supera el estadio de verdadera «storia di campanile»".

Con el fin de mitigar esta carencia e integrar el caso catalán en la dinámica general documentada en el occidente europeo, el presente estudio examina las iniciativas tomadas por parte de las autoridades municipales con el propósito de fortalecer la imagen de las instituciones locales en un ámbito fundamental: la creación de sedes permanentes destinadas a los órganos de gobierno, acción que se acompañó de medidas para mejorar la apariencia pública de sus oficiales. Dicho análisis se basa en una combinación de datos inéditos extraídos de varios archivos locales y notariales con fuentes secundarias de procedencia dispar. El objetivo final es comprobar hasta qué punto la situación económica de las administraciones municipales supuso, o no, un freno para un proceso deliberado de consolidación de su imagen corporativa y establecer cuáles son las causas que permiten explicar mejor esta dinámica.

\section{EL CONTEXTO: LA «CRISIS» DE LAS FINANZAS MUNICIPALES}

No obstante, antes de entrar en materia y en relación con esta última cuestión, la de las finanzas municipales, deben hacerse algunas consideraciones previas. Como es sabido, la historiografía de la Corona de Aragón ha hecho avances importantes en el estudio de las dificultades experimentadas por los gobiernos locales a partir de las décadas centrales del siglo XIV, poniéndolas en relación con los grandes paradigmas explicativos sobre la crisis de la Europa tardomedieval ${ }^{10}$. A grandes rasgos, frente a una visión muy negativa sobre los efectos de las guerras y de la creciente presión fiscal por parte de la monarquía, investigaciones más recientes han demostrado que, durante esta etapa, en los

\footnotetext{
${ }^{8}$ PUIG I CADAFALCH 1935. DALMASES, 1998. ESPAÑOL, 2002: 263-281. PLADEVALL, 2003: 179-190.

9 VIDAL, 2008. A propósito del problema señalado, podemos ver el caso emblemático de la casa de la ciudad de Barcelona en el que la mayoría de las noticias tradicionalmente manejadas por la historiografía fueron dadas a conocer por Duran i Sanpere en un trabajo clásico con una primera versión del año 1927 que, además, carece de aparato crítico: DURAN I SANPERE, 1971, vol. I: 279-323.

${ }^{10}$ Por citar sólo algunos de los estados de la cuestión más recientes sobre el conjunto de los reinos hispánicos, la Corona de Aragón y, finalmente, Cataluña: RODRÍGUEZ, 2012. IGUAL, 2007. FURIÓ, 2010. FELIU, 2004.
} 
territorios bajo los dominios de los reyes de Aragón se vivió una auténtica revolución financiera. El gran salto se produjo cuando las corporaciones - de entrada, y en especial, las municipales - optaron por la emisión de deuda pública a través de la venta de rentas vitalicias y perpetuas, cuyos intereses quedaron asignados sobre impuestos indirectos conocidos como sisas o imposicions ${ }^{11}$. Cuando estas eran insuficientes, o para hacer frente a otras necesidades, se emplearon también mecanismos de tasación directa, o sea derramas repartidas en función de la riqueza de cada contribuyente y, en ocasiones, se crearon incluso rudimentarios impuestos sobre la renta ${ }^{12}$.

La dinámica resultante de las demandas fiscales de la monarquía, los gastos generados por las obras en las murallas, el abastecimiento de víveres en coyunturas de carestía y, en última instancia, la carga derivada de la propia deuda contraída implicó un auténtico reto y entrañó dificultades de orden diverso para los gobiernos municipales. Pese a todo, estudios de caso sobre un conjunto representativo de poblaciones de Cataluña han demostrado que ello no perjudicó el avance de los principales sectores económicos ${ }^{13}$. Se ha observado, en especial, a través de la evolución de los precios de los arriendos de impuestos indirectos percibidos por los propios municipios, los cuales, junto a otros gravámenes como las lezdas de la ciudad de Barcelona o las exacciones aduaneras y sobre la producción y el comercio textil de la Diputación del General de Cataluña, no presentan cifras precisamente negativas desde 1360 en delante. En realidad, y teniendo en cuenta factores de corrección como la modificación de las tarifas, ponen de manifiesto un ascenso hasta las décadas de 1420 o 1430 -incluso con algunos repuntes en los decenios inmediatamente posterioresy un colapso cuya causa determinante fue el estallido de la guerra civil catalana en 1462. Todo ello permitiría sostener que, a pesar de un descenso paulatino en el consumo de productos básicos en localidades que padecían cierto estancamiento o retroceso demográfico, hasta las décadas centrales del siglo XV no se detecta una desaceleración de la actividad manufacturera, comercial y financiera $^{14}$.

Sea como fuere, más allá de la interpretación que pueda hacerse de la secuencia precisa de estos indicadores, lo que resulta innegable es que las propias exigencias de la monarquía y los cuantiosos donativos aprobados en cortes y parlamentos en las décadas de 1350 y 1360 sentaron las bases financieras de las administraciones municipales. Y estas administraciones, al menos en el

${ }^{11}$ FURIÓ, 1999. SÁNCHEZ FURIÓ y SESMA, 2007.

${ }^{12}$ Con todo, cualquier nueva medida al margen del consolidado binomio deuda-sisas requirió la aprobación de la monarquía o de la autoridad jurisdiccional correspondiente: VERDÉS, 2012.

${ }^{13}$ ORTI y VERDÉS, 2016.

14 ORTI, 2017. VERDÉS, 2019.

Hispania, 2020, vol. LXXX, n. ${ }^{\circ}$ 265, mayo-agosto, págs. 343-372, ISSN: 0018-2141, e-ISSN: 1988-8368 https://doi.org/10.3989/hispania.2020.009 
plano local, se convirtieron en los entes con mayor capacidad de punción fiscal, inversión y redistribución de renta. Los vectores de gasto antes apuntados casi no dieron margen para abordar otras inversiones. Con todo, a finales del siglo XIV y a inicios del siguiente, los mecanismos estaban consolidados $\mathrm{y}$, en cuanto se abrieron ventanas de oportunidad, los ediles locales trataron de abordar nuevos proyectos. Es justamente en este contexto de consolidación y afirmación frente al resto de instancias políticas en el que registramos las iniciativas encaminadas a reforzar los elementos identitarios por parte de las corporaciones municipales de varias poblaciones del Principado.

\section{LOS GOBIERNOS LOCALES EN LA TOPOGRAFÍA POLÍTICA URBANA}

De esta manera, para entender la génesis de las casas consistoriales, debe tenerse en cuenta en primer lugar el continuum de poderes seculares existente en los centros urbanos de la Cataluña bajomedieval y cómo este hecho condicionaba la topografía institucional ${ }^{15}$. Sin entrar en el caso mucho más complejo de la Iglesia, sabemos que, desde la Alta Edad Media, muchos centros urbanos se formaron alrededor de castillos u otros edificios fortificados, algunos de los cuales se hallaban bajo el control de los condes de Barcelona y posteriormente reyes de Aragón, quienes los utilizaban durante su itinerancia. Sin embargo, con el paso del tiempo los sucesivos soberanos acabaron disponiendo sólo de grandes palacios propios en la misma ciudad condal, en especial el Palacio Real Mayor con orígenes en el siglo XI. Posteriormente, jugaron el mismo papel la Aljafería de Zaragoza, la Almudaina de Palma de Mallorca y el Real de la ciudad de Valencia, además del castillo iniciado por Jaime II de Mallorca en Perpiñán en el último cuarto del siglo XIII. Y ello sin olvidar edificaciones que se incorporaron a sus dominios fruto de la expansión mediterránea de los siglos XIII-XV, como son el palacio normando de Palermo y el Castel Nuovo de Nápoles. Otros enclaves, en cambio, como los castillos reales de Lérida, Tortosa, Tarragona y Huesca perdieron progresivamente su función de residencia temporal de la monarquía, por lo que no acogieron programas arquitectónicos equiparables a los anteriores ${ }^{16}$.

Paralelamente, en muchas ciudades, desde los siglos XI y XII, había pequeños castillos o torres estratégicamente construidas para defender las puertas de

15 SABATÉ, 2003. Sobre la idea concreta de mosaico o continuum de poderes: ORTI, 2001. De todos modos, hay que destacar de nuevo que el ejemplo de la Corona de Aragón pocas veces ha integrado investigaciones de alcance europeo en las que se ha combinado la historia urbana de los centros de poder y su vertiente ideológica y política con la arqueología y el urbanismo como, por ejemplo, en la obra colectiva BOUCHERON y CHIFFOLEAU, 2004.

16 ESPAÑOL, 2001: 9-105. NAVARRO, 2005: 179-182. 
las antiguas murallas, de origen romano o carolingio. Se trataba de construcciones que, a pesar de ser de titularidad regia, en muchos casos habían sido concedidas en feudo a las sagas nobiliarias más prominentes, como sucedió, sin ir más lejos, en el caso de Gerona ${ }^{17}$.

Finalmente, a partir de las últimas décadas del doscientos, en las poblaciones de más relevancia se desarrollaron las cortes jurisdiccionales de los delegados territoriales ordinarios de la monarquía o de los grandes señores jurisdiccionales, los veguers y bailes ${ }^{18}$. Se situaron en edificios específicos - aunque sin dar lugar a verdaderos proyectos monumentales - , normalmente conectados con escribanías propias u oficinas notariales dada la intensa actividad documental que sus oficiales y auxiliares generaron ${ }^{19}$. También quedaron vinculadas con la prisión pública ${ }^{20}$.

A grandes rasgos, este fue el escenario en el que las autoridades municipales tomaron la decisión de desembolsar cantidades considerables de dinero para proyectar la imagen de su institución en un contexto de afirmación del poder que representaban. Según anticipábamos, la manifestación más clara de la dinámica mencionada fue la apertura de sedes estables para las corporaciones locales. Cabe añadir que lo hicieron sin partir de una base patrimonial propia que lo favoreciera. En efecto, en Cataluña, al igual que en Valencia y a diferencia de lo que ocurría en muchos núcleos urbanos del Reino de Aragón, de la Corona de Castilla y en especial de la Península Itálica, los concejos no disfrutaban de dominios territoriales propios ${ }^{21}$. Dicho en otras palabras, los gobiernos municipales catalanes, con muy pocas excepciones, no contaban con bienes inmuebles o fincas rústicas, ni percibían rentas agrarias; un elemento

17 CANAL et al., 2010: 66-67. En Barcelona, en cambio, las importantes tensiones del siglo $\mathrm{XI}$ contribuyeron al hecho de que la nobleza abandonara la ciudad condal como lugar de residencia: BANKS, 1992: 36-68.

18 SABATÉ, 2003: 389-403.

19 En el caso de la ciudad de Gerona, el edificio en el que se instaló la corte de los oficiales reales junto a la cárcel común en torno a 1320 perduró hasta finales de la época moderna. A pocos pasos se encontraba la sede de otra institución de referencia, la notaria real de la ciudad: GUILLERÉ, 1993, vol. I: 496. En villas como Castellón de Ampurias también se ha podido seguir la evolución de la curia, en este caso señorial, con un primer emplazamiento en las postrimerías del siglo XIII y un traslado a finales del decenio de 1330: FARÍAS, 2009: 344. Contrariamente, en lugares de relevancia indiscutible como Tortosa, las noticias sobre la sede de la corte del veguer son bastante inciertas antes de inicios del siglo XV, cuando pasó a acoger la prisión en una operación protagonizada por el ejecutivo municipal. Es posible que, en origen, se hallara en el mismo edificio que se convirtió en casa de la ciudad en torno a 1370: VIDAL, 2008: 69-70, 81-106.

${ }^{20}$ Sobre las cárceles propias de los oficiales jurisdiccionales del rey: SABATÉ, 2018: 132-135.

${ }^{21}$ MENJOT, 2007. Ello contrasta, pues, con el ejemplo de ciudades y villas aragonesas como Zaragoza (LAFUENTE, 2014) o Calatayud (DIAGO HERNANDO, 2006: 336-343). 
que, sin duda, también condicionó las circunstancias y el ritmo del proceso que nos ocupa ${ }^{22}$.

\section{LA PROGRESIVA CREACIÓN DE EDIFICIOS CONSISTORIALES}

Desde un punto de vista estrictamente cronológico, la historia de las casas consistoriales catalanas empieza con el caso excepcional de Perpiñán. En 1315 los habitantes de la entonces capital del reino de Mallorca recibieron el permiso del rey Sancho I para adquirir una tienda y otras pequeñas edificaciones anexas y adaptarlas como edificio comunitario. Aunque el núcleo original fuera ampliado en 1368 y en 1402, amén de reformas posteriores aún más importantes, recientes hallazgos arqueológicos certifican que materiales de madera que todavía conserva fueron efectivamente manufacturados en 1317 o en $1318^{23}$. Probablemente Perpiñán tratara de imitar los precedentes de localidades occitanas cercanas, como Narbona, Montpellier o Toulouse, donde las organizaciones municipales, los conocidos consulados, cristalizaron desde mediados del siglo XII y, ya en el siglo posterior, tuvieron cierta influencia en un paisaje arquitectónico hasta entonces dominado por los príncipes territoriales y los cabildos catedralicios ${ }^{24}$.

Dejando al margen el caso perpiñanés, la articulación de auténticas casas consistoriales en Cataluña se produjo a partir del último tercio del siglo XIV. De acuerdo con lo apuntado, la secuencia coincide con la del desarrollo de las instituciones municipales, cuyas estructuras — debemos insistir en ello- se fortalecieron en gran medida debido al aumento de la presión fiscal y a las consiguientes atribuciones en materia tributaria y financiera adquiridas durante las décadas centrales del trescientos ${ }^{25}$.

Durante esta etapa se consolidaron definitivamente las estructuras propias de representación de las comunidades locales que habían aparecido a lo largo

22 De hecho, también se ha considerado uno de los factores clave en el recurso a la emisión de rentas como instrumento de crédito, utilizando como garantía para el pago de los intereses las personas y bienes de cada uno de los habitantes de la comunidad: ORTI, 2005: 461-462.

${ }^{23}$ STYM-POPPER, 1954: 126-131. POISSON, 2000: 93-95.

${ }^{24}$ Un trabajo clásico sobre la difusión de estas estructuras en el Mediodía francés: GOURON, 1984. Con ciertos matices a propósito de Toulouse: BISSON, 1999. Tanto en Toulouse como en Narbona las incipientes corporaciones municipales adquirieron algún inmueble a finales del siglo XII o durante la primera mitad de la centuria siguiente: CAZES, 2017. CAILLE, 2004: 191. En el caso de Montpellier los cónsules compraron un primer edificio en 1205, aunque el hôtel de ville definitivo se instaló en otro adquirido en 1361: CHASTANG, 2013: 79-82, 204-207, 325.

${ }^{25} \mathrm{P}$. Orti ha propuesto, a partir del ejemplo de Barcelona, que alrededor de 1370 el gobierno municipal tomó la iniciativa frente al resto de instituciones presentes en la ciudad: ORTI, 2001: 36. Sobre la importancia indiscutible de la dinámica fiscal y financiera en el desarrollo de los entes locales: TURULL, 2000. TURULL y VERDÉS, 2006. 
de la segunda mitad del siglo XIII ${ }^{26}$. Entre finales de esta centuria y mediados de la siguiente en la mayoría de grandes poblaciones cuajaron órganos formados por un número limitado de representantes; de una veintena a un centenar según el tamaño de la localidad y, en cualquier caso, tendiendo a incluir desde los grupos más pudientes hasta diversos miembros del artesanado. Estos consejos sustituyeron a las antiguas asambleas de «todos» los varones cabeza de familia (las cuales, a partir de entonces, pasaron a convocarse de forma muy excepcional) y se convirtieron en el teórico órgano deliberativo o legislativo principal, así como la base para la elección y renovación de los oficios de la corporación local.

De todos modos, al frente de la administración municipal se hallaba siempre una instancia ejecutiva formada por equipos de tres a seis ediles (jurats, consellers, paers o cònsols, según las distintas denominaciones de cada lugar). Asimismo, en bastantes villas y ciudades, el ejecutivo estaba respaldado y se reunía con cierta frecuencia con un consejo restringido respecto a los consejos con varias decenas de representantes. En consecuencia, en determinadas coyunturas, estos últimos consejos más amplios quedaron relegados a un mero papel consultivo o de validación de grandes acuerdos como los tocantes a ciertas ordenanzas locales, el reparto de la carga fiscal, el endeudamiento colectivo o la elección de síndicos y mensajeros.

Habida cuenta de esta jerarquía de estructuras de representación u órganos de gobierno, debemos preguntarnos sobre los espacios donde se reunían en la etapa inmediatamente anterior a la que centramos el artículo. Así vemos que las excepcionales congregaciones extensas de los miembros de cada comunidad o los consejos de base con un mayor número de representantes que cuajaron en la mayoría de las poblaciones desde finales del doscientos se celebraban en espacios abiertos o dentro de las principales construcciones existentes en los centros urbanos, normalmente establecimientos religiosos. En este sentido, el Consejo de Ciento (con un centenar de miembros) de Barcelona se convocaba en el convento de la orden de los dominicos ${ }^{27}$. En Gerona, la institución análoga, formada por unos ochenta representantes, se reunía en la casa franciscana de la ciudad, al igual que en Tortosa o en Villafranca del Penedès - donde también se empleaban otros lugares_-, mientras que en Manresa los consellers

${ }^{26}$ Entre muchas otras referencias al respecto: BATLLE, 1988. NARBONA, 2007.

27 Según el relato fijado por Duran i Sanpere, que los especialistas consideran pendiente de revisión, hasta 1369 los ediles barceloneses se dieron siempre cita en el convento dominico de Santa Caterina, pero el conflicto resultante de un proceso de herejía iniciado por miembros de esta congregación contra un ciudadano de Barcelona motivó que en dicho año pasaran a reunirse en el convento de la orden franciscana. Inmediatamente, además, se decidió la adquisición de un inmueble para construir una sede propia: BESERAN, 2003a: 275. 
eran acogidos por los carmelitas ${ }^{28}$. Todo ello se explica, en parte, por la buena sintonía y las relaciones fluidas que, como es sabido, normalmente existieron entre las élites urbanas y las órdenes mendicantes ${ }^{29}$.

En villas donde estas últimas no llegaron a instalarse o lo hicieron con cenobios de poca entidad continuó vigente la opción de la iglesia parroquial — como sucedía en la villa señorial de Peralada con la iglesia de San Martín-, de otros edificios religiosos — por ejemplo, en Torroella de Montgrí se recurría a la capilla de San Antonio situada en la Plaza Mayor-o, a veces, de templos vinculados a centros asistenciales dependientes de los propios municipios, como la capilla de San Bartolomé del Hospital de Pobres que el consistorio de Igualada controlaba y tenía como lugar habitual de reunión ${ }^{30}$. Si bajamos eslabones en la red urbana, encontramos también asambleas locales al aire libre: en plazas públicas, frente a la iglesia o en sus cementerios, amén de las plazas de los castillos en localidades de señorío ${ }^{31}$.

En definitiva, antes de mediados del siglo XIV, la mayoría de las autoridades municipales del Principado no contaban con un edificio exclusivo para celebrar actos de elección u otras sesiones ordinarias y extraordinarias. Únicamente algunas poblaciones del área occidental, como Lérida y Cervera, disponían de una sala para el consejo local desde inicios del trescientos, singularmente para los encuentros que sólo implicaban a los miembros del ejecutivo y un pequeño grupo de asesores ${ }^{32}$. De hecho, no resulta raro tampoco que durante

${ }^{28}$ Respectivamente: GUILLERÉ, 1993, vol. I: 496. VIDAL, 2008: 69-70. COY, 1909: 589. TORRAS, 1998. Las corporaciones de ciudades de otros territorios cercanos con una larga tradición de autonomía urbana como Marsella tampoco disfrutaban de un edificio propio en estas fechas: OTCHAKOVSKY-LAURENS, 2016: 216-222.

${ }^{29}$ Se conoce bien, por ejemplo, a propósito de los franciscanos: WEBSTER, 1993: 85-87, 90-91.

${ }^{30}$ AHG, Notariales, Peralada, vol. 1464, s. d., 1384/02/21 (y ello, a pesar de que en Peralada, ya en 1416, como apuntaremos, aparezcan menciones a una casa del concejo para fines concretos). AHG, Notariales, Torroella de Montgrí, vol. 720, s. d., 1388/01/01. AHG, Notariales, Torroella de Montgrí, vol. 720 s. d., 1405/09/23. Cruz 1997: 24-27. En la misma línea, el primer edificio propio del gobierno municipal de Palma de Mallorca desde 1343 se emplazó en las dependencias de una institución hospitalaria preexistente y con la que convivió hasta mediados del siglo XV: CANTARELLAS y TUGORES, 2014: 118-125.

${ }^{31}$ Las fuentes notariales, a través de actas o contratos aislados, nos brindan una gran cantidad de ejemplos que aquí no podemos comentar.

${ }^{32}$ En este sentido, una casa de la paeria (o ejecutivo municipal) de Lérida ya aparece documentada a inicios de la década de 1340 (o incluso antes) como lugar habitual de encuentro de los regidores y varios prohombres del concejo (RIBALTA y TURULL, 1983: 23, 59, 67), aunque su ubicación era distinta de la del nuevo edificio adquirido en 1382 (BOLÓS y SÁNCHEZ, 2003: 62). En cuanto al caso mejor estudiado de Cervera, desde 1332 constaba una sala de la paeria o corporación en el mismo emplazamiento que el ayuntamiento actual, o sea en la plaza principal a la sombra de la iglesia parroquial. Sin embargo, en 1338 el edificio fue objeto de una primera reforma importante $y$, en décadas posteriores, se realizaron intervenciones en 
muchas décadas en la mayoría de los lugares estas reuniones restringidas de las autoridades municipales se celebraran en residencias particulares. Sin ir más lejos, en Gerona estaba establecida la costumbre de que el edil de más edad debía acoger en su vivienda los encuentros del equipo de seis regidores ${ }^{33}$. De este modo, las fuentes ilustran como cada año los objetos fundamentales e insignias de la institución municipal eran transportados al inmueble correspondiente $^{34}$. Por su parte, en Manresa, hasta aproximadamente 1480, la custodia de dichos objetos estaba a cargo del racional o interventor de las finanzas municipales $^{35}$. En cualquier caso, el conjunto estaba formado, en general, por los sellos, el pendón, el arca común y algún otro mueble que contenía los privilegios del municipio y el resto de documentos fundamentales ${ }^{36}$.

Frente a este panorama, a inicios del decenio de 1370 el ejemplo de la ciudad de Barcelona se convirtió en un auténtico hito para la construcción de dependencias municipales específicas. De esta forma, a lo largo de la misma década o en las dos siguientes, otras poblaciones como Tortosa, Tarragona, Vic, Balaguer, Puigcerdà o Castelló de Ampurias recogieron el testigo ${ }^{37}$. Asimismo, en 1382 se habilitó un nuevo edificio más espacioso para el gobierno local en Lérida, y el año siguiente en Gerona se tomaron acuerdos en este sentido, aunque entonces no fructificaron ${ }^{38}$. En síntesis, al igual que sucedió en otros ámbitos como la recopilación del corpus de ordenanzas municipales, la decisión de invertir en una casa para las instituciones municipales se expandió a través de

porches y tejados hasta una nueva serie de obras con gran impacto urbanístico a partir de 1480 (VERDÉS, 2004: 729-731).

33 ACA, C, reg. 1797, f. 29v-30r, 1381/04/02. AMGi, I.3.3.1.5., leg. 2, reg. 1, ff. 360r-361r, c. 1390. AMGi, Urbanisme i Obres, reg. 11670, f. 2v, 1384/11/09.

${ }^{34}$ En cualquier caso, todos estos elementos no son una cuestión baladí, ya que constituyen verdaderos marcadores de la autoridad municipal y herramientas para el ejercicio cotidiano del poder local: JEAN-COURRET, LAVAUD, PETROWISTE y PICOT, 2016: 11-14.

35 VERDÉS, 2020: 167-168.

${ }^{36}$ En Gerona se detalla, por ejemplo, que estos bienes consistían en «los tapits de la paret e de la taula et unum banchal que omnia sunt cum signo dicte civitatis ac caxiam et sigillium ipsius civitatis et scrineum majorem», AMGi, MdA año 1403, ff. 10r-v, 1403/01/03. En Manresa se refieren bancos, un cobertor con las señales de la ciudad, banderas, pendones y arquibancos con pergaminos y escrituras: VERDÉS 2020: 166-168.

${ }^{37}$ Otros ejemplos destacados, aunque más tardíos, son el de la Seu de Urgell, con una casa de la ciudad que se superpuso a un antiguo hospital alrededor de 1470. Entre las últimas décadas del siglo XIV y mediados de la centuria siguiente también se crearon casas consistoriales de características similares en el norte del reino de Valencia: RIU y BARRERA, 2003: 180182. Acerca del caso de Castelló de Ampurias: PUJOL, s. d. Más adelante, en algunas localidades se reemplazó la primera casa por otra, como parece que sucedió en Tarragona, cuyo municipio compró un nuevo inmueble en 1425, CORTIELLA, 1994: 162-163.

38 BOLÓS y SÁNCHEZ, 2003: 62. En cuanto a Gerona: AMGi, MdA año 1383, ff. 3r-v, $1383 / 01 / 08$. 
un verdadero proceso de osmosis ${ }^{39}$. Dicho proceso, como se ha apuntado, se inició en el último tercio del siglo XIV y a finales del siglo siguiente continuaba aún abierto. Y ello sin que nunca mediara una disposición de alcance general similar a la documentada en otros territorios, como Castilla en $1480^{40}$.

En efecto, a lo largo del cuatrocientos muchas poblaciones de segunda y tercera fila se incorporaron a esta dinámica ${ }^{41}$. Descartando ofrecer un repertorio exhaustivo que superaría los límites de este artículo, podemos señalar unos pocos casos del área nororiental, seguramente con ejemplos más tardíos en comparación con la Cataluña central y occidental. En Figueras se documenta una «domus consilii» en 1428, mientras que en Peralada aparece ya en 1416, pero aún no acogía todos los actos del consistorio. En Rosas se conoce, por referencias indirectas, un edificio municipal anterior a 1500 situado en el barrio portuario que servía a la vez de sede de la corporación local, de tienda de abasto y de atarazana. Contrariamente, en la villa de Besalú no había aún casa consistorial en 1446, cuando una concesión real permitió aprovechar el solar de la antigua sinagoga para construirla junto a la cárcel, el archivo y la sede de una institución benéfica local ${ }^{42}$.

\section{LAS PRIMERAS CASAS DE CONCEJO: UNA ARQUITECTURA FUNCIONAL}

Más allá de la cronología, un rasgo común en la mayoría de los proyectos de casas consistoriales de la Cataluña del periodo es que no se materializaron en solares pendientes de edificar. Debido, en parte, a la ausencia de propiedades territoriales de titularidad municipal antes comentada, los ediles tuvieron que rehabilitar y adaptar antiguas casas, normalmente grandes viviendas de familias opulentas o de individuos con ciertas conexiones con los propios entes

${ }^{39}$ La idea de la emulación e, incluso, la de competencia recurrente en procesos constructivos paralelos se ha propuesto sobre todo con relación a las ciudades de Barcelona y Valencia a finales del siglo XIV, SERRA DESFILIS, 2010: 64-65.

40 Es bien conocida la ordenanza de las Cortes de Toledo de 1480 que, en una campaña de fomento por parte de los Reyes Católicos del ornato de las ciudades castellanas, obligaba a la creación de casas concejiles en las plazas del mercado de todos los núcleos urbanos: NIETO SORIA, 1999: 342. MARTÍN CEA, 2013: 157-159. Sin embargo, bastantes autores han comprobado que la medida no se aplicó de manera generalizada, ni mucho menos.

${ }^{41}$ Salvando las distancias en la densidad urbana y la evolución de los entes municipales, algo parecido sucedió en el reino de Aragón, donde el modelo se expandió a lo largo del siglo XVI a partir de la capital, Zaragoza (con una mención esporádica de edificio consistorial desde 1311 y mejor documentada a partir del decenio de 1360), la ciudad de Huesca y algunas pocas villas que ya contaban con casa concejil desde la centuria anterior: LOMBA, 1989: 36, 175, 236, 276. VELASCO 2015: 301-307.

${ }_{42}$ ACGAX, Notaries Foranes, SP-131, s. d., 1428/04/27. AHG, Notariales, Peralada, vol. 1202, s. d., 1416/05/21. PUJOL, 1997: 179. RIERA, 2006: 576, doc. 403 (1446/11/07, Barcelona). 
locales. Podemos ver un par de ejemplos esclarecedores al respecto. El consistorio de Barcelona compró el domicilio de un notario que precisamente servía a la institución, mientras que los paers (o regidores) de Lérida hicieron lo propio con una residencia levantada en distintas etapas desde el siglo XII y poseída por los Sanaüja, miembros de la nobleza regional. Al menos en este último caso se ha comprobado que, en una fase inicial, se introdujeron pocos cambios en el edificio ${ }^{43}$. Al contrario, la casa del concejo de Vic destaca entre el resto por el hecho de que las estructuras preexistentes fueron casi en su conjunto demolidas $^{44}$.

No obstante, la compra de una casa para transformarla en las dependencias de los respectivos gobiernos locales constituía sólo un primer paso en un proceso que se prolongó durante décadas o, incluso, centurias. Esto significa, pues, que, con excepciones como los ejemplos mencionados de Barcelona o Vic, los edificios municipales inicialmente no fueron dotados de verdaderos programas arquitectónicos o decorativos en su exterior hasta bien entrado el siglo $\mathrm{XVI}^{45}$. $\mathrm{Y}$ es que las primeras acciones podían reducirse, por ejemplo, al grabado del escudo o la heráldica de la ciudad en una de las puertas ${ }^{46}$.

Por ende, las casas consistoriales construidas durante la segunda mitad del trescientos o ya en la centuria siguiente eran, en general, construcciones relativamente modestas y quedaban muy lejos de los edificios análogos de Flandes o el norte de Francia, con sus majestuosos belfries/beffrois - o torres-campanario-, o los palazzo pubblici de la Toscana u otros territorios de la Península Itálica $^{47}$. Los elementos externos más llamativos de los ayuntamientos catalanes, que en bastantes casos aún pueden admirarse, fueron elaborados entre los

${ }^{43}$ Respectivamente: BESERAN, 2003b: 183. RIU y BARRERA, 2003: 180. Asimismo, en Gerona, en 1414, se adquirió por el precio de 12.000 sueldos barceloneses una residencia situada en la céntrica plaza de Les Albergueries a la hija y heredera del jurista Francesc Santdionís, miembro de una familia del patriciado local, descendiente de un médico al servicio de la casa real, GIRONELLA, 2013: 35-38.

${ }^{44}$ En concreto, se obtuvo permiso para derrumbar una casa entera y levantar un nuevo edificio, PUIGFERRAT, 2003: 189-190.

${ }^{45}$ De nuevo el caso pionero, seguramente, fue el de la casa de la ciudad de Barcelona, cuya imponente fachada gótica ya fue construida a inicios del siglo XV. Hasta entonces se considera que el edificio empezado a reformar a partir de 1369 constituía un conjunto heterogéneo con propósitos, en esencia, funcionales, BESERAN, 2000a: 287.

${ }^{46}$ Como se hizo en el portal de la casa concejil de Gerona un par de décadas después de inaugurarse, AMGi, MdA año 1432, f. 68r, 1432/12/30. Sobre la importancia de estas insignias, presentes tanto en la decoración arquitectónica como en la sigilografía y, según veremos, en muchos otros objetos propios de la corporación, BEDOS y REZAK, 2002.

${ }^{47}$ Una panorámica sobre los edificios promovidos por los gobiernos municipales en Flandes y Brabante a inicios del siglo XIV como símbolo de su autonomía y pujanza: COOMANS, 2007: 188-190. Visiones más matizadas sobre la supuesta confrontación con el poder principesco que representan: LECUPPRE-DESJARDIN, 2003: 33-35. A propósito del conjunto del reino de Francia: SALAMAGNE, 2015. 
siglos XVI y XVIII, si no más tarde ${ }^{48}$. De hecho, en la línea de lo que recientemente se observa en los palacios de las comune italianas durante su primera fase de desarrollo - anterior a 1300 —, los edificios de los gobiernos municipales catalanes de los siglos XIV y XV seguramente no buscaban impresionar desde un punto de vista frontal a los vecinos de la localidad o a sus visitantes, sino que su principal función era la de ofrecer un espacio interno para la reunión mediante varios compartimientos y niveles distintos de privacidad a partir de planos horizontales ${ }^{49}$.

Con respecto a la estructura interior de estas casas concejiles habilitadas entre finales del siglo XIV e inicios de la centuria siguiente, normalmente estaban formadas por dos salas o más ${ }^{50}$. Una de ellas, de dimensiones mayores, se reservaba para la celebración de las asambleas amplias, mientras que la otra era destinada a sesiones del ejecutivo o de consejos restringidos, de acuerdo con la estructura de órganos políticos comentada antes. Así vemos que en la casa del concejo de Barcelona sobresalían el llamado Saló de Cent, construido entre 1369 y 1372 como gran sala de reuniones dentro del patio interior de la casa acabada de adquirir, y el salón llamado del Trentenario (o consejo restringido), existente desde, al menos, $1388^{51}$. Dependiendo del lugar, los espacios podían dar pie a dos plantas ${ }^{52}$. Cuando esto sucedía, el nivel a pie de calle, formando parte de una especie de patio interior habitualmente dotado de pórticos, podía utilizarse para varios fines, a saber, encuentros de hombres de negocios, ciertas celebraciones o actos de protocolo, y varios procedimientos ligados al sistema fiscal de base municipal, entre ellos el control de pesos y medidas.

Podemos verlo en el caso de Gerona. La nueva casa consistorial inaugurada en 1414 estuvo estrechamente vinculada a la creación de una lonja ${ }^{53}$. De ahí que

48 GARGANTÉ, 2004. BESERAN, 2003a.

49 DIACCIATI y TANZINI, 2014: 62-65.

50 Puede compararse su estructura con la estudiada a propósito de las casas consistoriales aragonesas de los siglos XVI y XVII, LOMBA, 1989: 95-114.

${ }^{51}$ BESERAN, 2003a: 275-276. En el caso de la ciudad de Gerona, varias informaciones dispersas y, sobre todo, el ritual anual de elección de nuevos cargos el día 1 de enero nos informan de la coexistencia de una sala llamada del consell general y de otra, en apariencia menos espaciosa, denominada del parlamento, además, como veremos, de la sala del archivo, AMGi, MdA año 1421, ff. 2r-11r, 1421/01/01. En la casa de la ciudad de Tortosa también se habla de dos salas donde se reunía el consejo municipal, amén del archivo y de un altar, VIDAL, 2008: 69-70.

52 El edificio del concejo de Vic es muy ilustrativo, PUIGFERRAT, 2003: 190. Otro buen ejemplo es el de Tortosa, VIDAL, 2008: 69-71. En Puigcerdà también se deduce la existencia de dos niveles, la «casa sobirana» y la «casa jusana», en un inmueble levantado en algún momento pendiente de determinar entre 1345 y 1399, ACCE, Fons municipal Puigcerdà, Registres de consells, 1399-1407, f. 2r, 1399/07/08.

${ }_{53} \mathrm{Sin}$ poder adentrarnos en el asunto, las constricciones legales que impedían a las autoridades municipales reorientar recursos fiscales, al margen del pago de los intereses de la deuda, 
acabara acogiendo las reuniones de los miembros del Consulado de Mar o corporación local de mercaderes ${ }^{54}$. De hecho, no hay que olvidar la relación que se establece igualmente en otras latitudes entre casas del común y lonjas o centros de intercambio mercantil ${ }^{55}$. Al cabo de poco, el edificio devino también uno de los lugares de referencia en las celebraciones del Corpus Christi ${ }^{56}$. Asimismo, en relación con el ámbito económico, en 1451 se habilitó en ella una alhóndiga o tienda del grano, otorgando así un puesto estable a esta administración municipal hasta entonces discontinua, con el fin de aumentar los ingresos fiscales mediante la centralización de la venta de cereal panificable ${ }^{57}$.

Por otra parte, en las casas del concejo había casi siempre una habitación específica habilitada como archivo del municipio, o sea un lugar cerrado para la custodia de la documentación vinculada a la institución ${ }^{58}$. Nos referimos, en

hizo que algunos de los primeros proyectos de casa consistorial partieran de licencias para crear un nuevo impuesto indirecto, a priori destinado a la construcción de una lonja mercantil. Lo vemos justamente en las experiencias de Gerona y de la villa de Castellón de Ampurias. En la primera se recurrió a un privilegio de 1385 para imponer una nueva exacción que se asignó al censal emitido para financiar, en 1414, la compra del inmueble que se adaptó como casa concejil, REIXACH, 2019, vol. I: 173, 223-225, con precisiones bibliográficas al respecto. Ello supuso que el nombre oficial del edificio fuera el de Nueva Lonja hasta 1446: AMGi, MdA año 1446, f. 80v, 1446/09/06. En Castellón se documenta un privilegio, equivalente al de Gerona, expedido en marzo de 1386, aunque allí las obras ya fueron contratadas en septiembre de 1393, dando lugar a un edificio con una sala y una galería aneja - probablemente con funciones de lonja - en la vertiente oriental: PUJOL, s. d.

${ }^{54}$ Aunque entre 1414 y 1438 sus representantes aún renovaran los cargos y se reunieran esporádicamente en la antigua canónica de San Martín Sacosta (AHG, Notariales, Girona-01, vol. 389, ff. 126r (1421/10/29) - 134r (1438/10/29), en algún momento se apunta que el cancel situado frente a la casa concejil había pasado a acoger las sesiones de la corte jurisdiccional propia del Consulado de Mar, con lo que se consumó su integración final en la sede municipal, AMGi, Borradores Manuals d'Acords, 1427, f. 98r, 1427/01/27.

55 SALAMAGNE, 2015: 35-38.

${ }^{56}$ En concreto, en torno a 1430, ya había cuajado la costumbre de celebrar durante el domingo antes de Corpus una recepción con un refrigerio en el que participaban los jurats $\mathrm{y}$ otros ciudadanos: AMGi, I.3.3.1.2., leg. 8 f. 34r, 1432. AMGi, I.3.3.1.2., leg. 10, reg. 1, f. 93v, 1437. AMGi, I.3.3.1.2., leg. 10, reg. 6, f. 87r, 1438. A propósito de las celebraciones en las ciudades hispánicas bajomedievales, NARBONA, 2017: 164-174.

${ }^{57}$ Las cuentas de las obras se hallan en: AMGi, I.2.2., leg. 5, reg. 2, 1451. En Cervera, asimismo, se registra el traslado del peso de la harina y otro propio del rey debajo de un pórtico de la casa consistorial: VERDÉS 2004: 738-739. Sobre estas instituciones dedicadas al abastecimiento frumentario: MORELLÓ, 2015.

58 VERDÉS, 2010: 159-161, 190. En el caso de la casa concejil de Barcelona sabemos que ya incluía un archivo desde, como mínimo, el año 1388: BESERAN, 2003b: 185. De todos modos, el ejemplo mejor estudiado de estos archivos municipales es el de la ciudad de Tortosa: CURTO, 2001. Serían de interés comparaciones con casos del Mediodía francés que han sido objeto de análisis pormenorizados, por ejemplo, en Montpellier, CHASTANG, 2013: 65-89, 229-274. Sobre la importancia del registro escrito en la construcción de la identidad urbana en el reino de Valencia y otros territorios de la Corona de Aragón, BARRIO, 2009-2010. 
concreto, a provisiones y cartas reales dirigidas a la comunidad, privilegios concedidos por la monarquía u otros poderes y cartularios o libros donde se hacían compilaciones de los más antiguos y significativos ${ }^{59}$. Igualmente tendían a situarse en estos espacios unos pocos armarios de madera y, sobre todo, arcones, cofres y cajas con libros de cuentas ya auditadas de los tesoreros $\mathrm{u}$ otros oficiales, cuadernos de recaudación de impuestos, padrones y demás registros de carácter fiscal ${ }^{60}$. Vale la pena insistir que hasta la creación de sedes específicas para los órganos de gobierno local esta creciente masa documental debía ser trasladada periódicamente, con los problemas de conservación que ello acarreaba. De ahí que en el siglo XIV puedan hallarse ordenanzas en distintos lugares en las que se urgía a los habitantes de la población a devolver cada cierto tiempo volúmenes o cuadernos que pertenecían a la administración municipal $^{61}$.

Otras secciones secundarias de las nuevas casas consistoriales podían reservarse para aposento de los oficiales que mantenían una relación cotidiana con el edificio y la corporación como el escribano o el macero ${ }^{62}$. En el caso de Barcelona destaca especialmente la estancia de otro oficial con un papel crucial, el raciona $l^{63}$. Todo ello sin olvidar salas dedicadas al almacenaje de armas, junto a instrumentos originales de pesos y medidas y herramientas varias en poder del consistorio, así como letrinas ${ }^{64}$.

59 Han sido editados y publicados la mayoría de los volúmenes de esta tipología de un gran número de ciudades y villas catalanas, normalmente elaborados a partir de la década de 1330 (aunque en muchas poblaciones no sucedió hasta los siglos XV o XVI) e identificados por el color de sus lujosas encuadernaciones. Con todo, carecemos de una comparación sistemática del contenido, la estructura y los procesos de elaboración de todos estos libros de privilegios en el conjunto del Principado, al igual que se ha reclamado para otras áreas como la Provenza, HÉBERT, 2008.

${ }^{60}$ Vemos una descripción de estos elementos en sendos inventarios ya publicados del archivo de la casa concejil de Gerona en 1459 y 1484, BATLLE, 1951: 186-187, 189-190. A propósito de la custodia de toda la documentación mencionada, que acabaron asumiendo los racionals en poblaciones como Barcelona o Manresa: VERDÉS, en prensa. Agradezco al autor la posibilidad de consultar este trabajo antes de ser publicado.

${ }^{61}$ Vemos ejemplos de ello en Gerona, Tarragona o Manresa: CODINA y PERIS, 1985: 200. COMPANYS, 2009: 21-31. TORRAS, 1996: doc. 128 (1393/03/25).

${ }^{62}$ Por ejemplo, en Tarragona, cuando se proyectó la nueva casa, en 1425 , se dispuso que debía acoger la residencia del escribano y del mensajero: CORTIELLA, 1994: 162-163. Algo parecido sucedía en Cervera: VERDÉS 2004: 583. Según hemos apuntado, en Barcelona la casa del escribano jugó un papel clave en el propio desarrollo del conjunto, BESERAN, 2003a: 287.

${ }^{63}$ VERDÉS, en prensa.

${ }^{64}$ En Gerona se acabó acordando, en 1442, que el armamento (en especial, bombardas y ballestas) de titularidad municipal, que hasta entonces se hallaba en una torre de las murallas, fuera puesto a buen recaudo en la nueva casa del concejo: AMGi, MdA año 1442, ff. 98r-v, 1442/12/20. Desde sus inicios, el edificio también contó con letrinas: AMGi, MdA año 1419, f. 10v, 1419/01/23. BATLLE, 1954: 187-188. 
En paralelo a estos espacios con funciones claras, en ciudades como Barcelona o Gerona, a las dependencias de la institución municipal se añadió un vergel con naranjos ${ }^{65}$. Se trata de un elemento importado del mundo islámico con alusiones alcoránicas, presente en palacios y fortalezas de toda la cuenca mediterránea $\mathrm{y}$, desde inicios del siglo XIV, en muchas residencias reales de la Corona de Aragón ${ }^{66}$.

Finalmente, en bastantes casas consistoriales se acabaron añadiendo pequeñas capillas. En Barcelona ya se habilitó una entre los años 1401 y 1405, pero en otras poblaciones se trata de proyectos más tardíos. En Gerona se inició uno en 1454, aunque, después de muchas interrupciones, la obra definitiva no se concretó hasta las postrimerías de la década de 1490. Justo en 1494 es cuando arranca también la construcción de la capilla de la paería de Cervera ${ }^{67}$.

\section{EL INCREMENTO DEL ORNATO MUNICIPAL A PARTIR DEL SIGLO XV}

Como se ha dicho, estas primeras edificaciones municipales fueron relativamente simples, especialmente si las comparamos con las de otros casos europeos coetáneos como la Península Itálica o Flandes. Algo similar se observa en cuanto a la decoración y el ornato, aunque ello no obsta para que poco a poco se detecte un incremento de aspectos que contribuirían a crear una verdadera escenografía política, consolidada durante la época moderna.

En primer lugar, las mencionadas capillas, a pesar de no implicar grandes transformaciones arquitectónicas, fueron dotadas de valiosos retablos con una iconografía que tendía a incluir a la virgen rodeada de los santos patronos de la población y de la figura de sus representantes municipales ${ }^{68}$. Obviamente, constituían una muestra de fe o piedad pero, al mismo tiempo, se convirtieron en

${ }^{65}$ En la casa de la ciudad de Barcelona, menos de dos años después del inicio de su largo proceso constructivo, ya se plantaron naranjos en un patio del edificio (BESERAN, 2003b: 184). En Gerona también se documentan desde los primeros decenios de existencia del edificio comunal a raíz de los cuidados periódicos que recibían: AMGi, I.3.3.1.2., leg. 10, f. 109r, 1437. AMGi, MdA año 1447, f. 82r, 1447.

${ }^{66}$ ADROER, 2003. Incluso en algunas residencias de la alta nobleza, como el palacio de los condes de Ampurias en Castelló de la década de 1370, había un lugar para este simbólico frutal, GIRONELLA, 2011: 259. La lonja de mar de Barcelona contaba también con un frondoso vergel con naranjos que cautivó a muchos viajeros a lo largo del siglo XV, BERNAUS, 2003: 215. Ya en el siglo XVI en el palacio de la Diputación del General de Cataluña se habilitó el célebre Patio dels Tarongers, CARBONELL, 2015, vol. I: 63, 68-69 y vol. II: 336-346.

${ }^{67}$ Sucesivamente: Beseran, 2003b: 188-189. BATLLE, 1970: 317-320. VERDÉS, 2004: 731. En la casa de la ciudad de Valencia se identifica una desde el año 1395, pero la que acabó gozando de continuidad fue erigida un siglo después: SERRA DESFILIS, 2004: 84-85, 94-95.

${ }^{68}$ Entre otros casos que deberían estudiarse a fondo, alrededor de 1437, en Gerona se encargó un pequeño retablo con una imagen de la virgen: AMGi, I.3.3.1.2., leg. 10, f. 109v, 
una demostración del poder de las autoridades municipales y una prueba del honor de la corporación que dirigían. La forma con la que los miembros del Consell de Cent de Barcelona justificaron la decisión tomada en 1443 de ordenar un nuevo retablo para la capilla de la casa de la ciudad lo muestra con claridad. Querían sustituir un retablo pintado en 1410 porque se consideraba que no contribuía al decoro de la capilla y, según añadieron, no causaba ningún impacto especial a la gente que lo observaba («no és tengut en stima alguna per tots aquells qui ho miren, axí estrangers com altres»). Para ello se comprometieron a encontrar al pintor «millor e pus abte (...) que encerchar e trovar se posqués» ${ }^{69}$. El resultado fue la magnífica tabla de la Mare de Déu dels Consellers, obra de Lluís Dalmau, creando una escenografía que se acompañó de ricas vidrieras en las que estaban representadas las virtudes cardinales, así como de otros elementos ornamentales ${ }^{70}$. Al cabo de un año, también se encargó un espléndido retablo para la capilla de la casa de la Paería de Lérida con características similares ${ }^{71}$.

Todas estas piezas contribuyeron a aumentar el valor de un mobiliario que, hasta entonces, objetos cotidianos al margen, estaba encabezado por bancos, bancales y tapices para las paredes. Todos incluían la correspondiente heráldica de la corporación municipal - en los núcleos de realengo muchas veces combinada con las armas de la monarquía, presente también en otros objetos emblemáticos del municipio como la vara del macero ${ }^{72}$.

$\mathrm{Su}$ disposición, además, se fue perfeccionando. Si en un primer momento nos referíamos a los continuos traslados entre sedes todavía provisionales o a salas que parecían auténticos almacenes, durante el siglo XV vemos como, por ejemplo, en Cervera se exponían de forma deliberada ballestas y escudos con los símbolos de la villa en los muros de la casa consistorial ${ }^{73}$. A partir de esta

1437. En 1498, si se trataba del mismo, consta que también incorporaba la figura del arcángel san Miguel, patrón del oratorio municipal, BATLLE, 1964-1965: 379.

${ }^{69}$ AHCB, 02.01/1.B.II-3, 1442-1446, f. 36v-38v, 1443/06/05. DURAN I SANPERE, 1971, vol. I: 295.

70 MOLINA 1999. SALVADÓ, BUTI, RUIZ QUESADA et al., 2008. Sobre las vidrieras en concreto: DURAN I SANPERE, 1971, vol. III: 248-252. Resulta interesante comparar estos programas iconográficos acerca de la práctica virtuosa del gobierno y la justicia con los introducidos en salas interiores de edificios municipales de los antiguos Países Bajos durante el siglo $\mathrm{XV}$, a su vez, conectados con los de palacios comunales italianos de la centuria precedente: LECUPPRE-DESJARDIN, 2003: 32-33.

71 PUIG, 2003: 309-313. En las mismas fechas que la ciudad de Barcelona también fue contratado un majestuoso e innovador retablo para la capilla de las Casas del Puente o sede consistorial de Zaragoza: VELASCO 2015: 308-317.

${ }_{72}$ Para referencias tocantes a Gerona y Manresa, véase la nota 36. A propósito de la figura del macero o verguer: VERDÉS, 2009-2010: 158, 161-162.

${ }^{73}$ Se ha propuesto que, al mismo tiempo, podía tratarse de un recurso para la propia defensa de las autoridades municipales en momentos de tensión, VERDÉS 2004: 688-689. 
época también se hallan indicios de la existencia de libros emblemáticos situados encima de atriles y encadenados, como seguramente sucedía con el Dotzè del Crestià de Francesc Eiximenis en Gerona, o en otras poblaciones con recopilaciones de privilegios, costumbres locales o incluso padrones de riqueza. Todas estas piezas contribuían al relato interno de cohesión y buena ciudadanía, a la par que lo proyectaban hacia visitantes y gente externa ${ }^{74}$.

En definitiva, la forma en la que el gobierno municipal era visto por el entorno preocupaba cada vez más a los magistrados locales. De ahí que, en paralelo, se incrementara el cuidado de la apariencia de los miembros del ejecutivo, en especial, a propósito de la ropa emblemática que llevaban. La gramalla o larga túnica hasta los pies se convirtió en todo un símbolo del poder municipal en Cataluña hasta finales de la época moderna ${ }^{75}$. Esta atención por la indumentaria de los ediles como cabezas visibles de las instituciones locales ya se manifestaba, por ejemplo, en Perpiñán en la década de 1320 y, a lo largo del cuatrocientos, alimentó varios debates en Cervera, en Vic, en Puigcerdà $\mathrm{y}$, como hemos visto al principio, en Gerona ${ }^{76}$. En general, la idea es que debía prevalecer la uniformidad, la calidad de las telas y, asimismo, el brillo, la intensidad y la luminosidad de los colores, destacando, por encima de todos, el rojo, emblema de riqueza tradicionalmente vinculado a la monarquía y, por extensión, al poder político ${ }^{77}$. Así, la correcta vestimenta de los representantes municipales permitiría transmitir una imagen de pujanza y buen orden. Del mismo modo, se supervisaban estrechamente los ropajes oficiales de maceros, trompetas o atabaleros $\mathrm{y}$, ante todo, el modo de vestir de los embajadores enviados a la corte real o como síndicos en las asambleas de cortes y parlamentos ${ }^{78}$. $\mathrm{Y}$ es en este contexto que en muchas poblaciones se ordenaba comprar las mejores telas para elaborarlos, aunque tuvieran que irse a buscar expresamente a Barcelona ${ }^{79}$.

74 VERDÉS, 2009-2010: 159.

75 Sobre la importancia de los códigos de vestir durante el periodo GARCÍA MARSILLA 2017.

${ }^{76}$ Sucesivamente: DAILEADER, 2000: 197-198. VERDÉS, 2004: 579-582. SABATÉ, 2013: 194-196. BOSOM y VELA, 2007: 309-310. Por ejemplo, en Gerona, un decenio después del acuerdo de 1424, se consideró que las gramallas de los jurats no podían hacerse de paño oscuro como había sucedido en demasiadas ocasiones recientemente, sino que se les tenía que obligar a encargarlas de telas de un color «apparentis», es decir, vistoso, AMGi, MdA año 1434, ff. 5v-6r, 1434/01/01.

77 PASTOUREAU, 2016: 69-73. Sobre la evolución de las tendencias en los colores a propósito del ejemplo de Flandes, donde el rojo de la indumentaria municipal fue progresivamente substituido por el negro: MUNRO, 2007.

78 VERDÉS, 2005: 192-198.

79 En 1416, por ejemplo, los regidores de Gerona contactaron con naturales de la capital gerundense afincados en Barcelona para que rebuscaran en tiendas especializadas de la ciudad condal, compararan precios y consiguieran telas con guarniciones de oro de Luca y de color rojo, más precisamente, de un rojo de oro de Colonia, AMGi, I.1.2.1., leg. 8, reg. de 1416-1418, 


\section{CONSIDERACIONES FINALES}

El análisis de algunas de las principales estrategias empleadas por las administraciones locales a la hora de definir su posición dentro del paisaje simbólico de los centros urbanos ha puesto de relieve varias cuestiones. En primer lugar, se hace evidente una cronología que coincide con la que se conoce del propio desarrollo institucional de los municipios catalanes y en el que las dinámicas fiscales de las décadas centrales del siglo XIV tuvieron una gran repercusión. No en vano, es a partir del último tercio de la centuria y no antes que, en una primera fase, Barcelona y las principales ciudades y villas catalanas, $y$, posteriormente, otras localidades de rango inferior empezaron a crear sedes estables para las respectivas corporaciones. Lo hicieron en el tránsito del trescientos al cuatrocientos, cuando había disminuido la presión fiscal y se habían completado los grandes esfuerzos que exigieron las obras de las murallas, un proyecto promovido en muchos casos por la monarquía pero que sufragaron las arcas locales. Y es que las inversiones para comprar inmuebles que se destinarían a casas de concejo y que se irían mejorando progresivamente sólo fueron posibles gracias al entramado tributario y financiero propio de las haciendas locales que se habían consolidado en la fase crucial del tercer cuarto del siglo XIV.

Por otra parte, estas primeras casas concejiles, tal vez con la excepción de la de la ciudad condal, fueron edificios relativamente modestos hasta bien entrado el siglo XV o incluso más tarde. A la vista de su estructura arquitectónica, nada permite suponer que pretendieran competir en altura, o sea, reclamando un espacio en el skyline urbano, con castillos, torres y grandes edificios religiosos, lo cual no significa que el equilibrio siempre difícil entre utilitarismo y honor no se decantara a veces a favor de lo segundo. De ahí que construcciones en origen funcionales que acogían reuniones y muchas otras actividades vinculadas al consistorio, con el tiempo, tendieran a incorporar más elementos de decoración.

De entrada, todo este proceso no concordaría con los postulados tradicionales sobre el devenir económico de Cataluña y otros territorios de la Corona de Aragón desde mediados del siglo $\mathrm{XIV}^{80}$. Al contrario, reforzaría la idea de que, lejos de una asfixia absoluta, las arcas públicas siguieron drenando y distribuyendo recursos, a medida que superaban ciertas coyunturas críticas concretas. No obstante, debería comprobarse también si realizar inversiones destinadas a

ff. 2r-v, 1416/01/01. Este afán se hacía igualmente patente en los protocolos seguidos en las festividades o en actos públicos como las entradas reales: RAUFAST, 2007 (entre otros trabajos del mismo autor y con toda la bibliografía que recoge). NARBONA, 2017: 96-104.

${ }^{80}$ Una disociación entre supuesta crisis y actividad constructiva que también se desprende de estudios puntuales sobre otros ámbitos de la corona, como Mallorca durante la primera mitad del siglo XV: CATEURA, 1996.

Hispania, 2020, vol. LXXX, n. ${ }^{\circ}$ 265, mayo-agosto, págs. 343-372, ISSN: 0018-2141, e-ISSN: 1988-8368 https://doi.org/10.3989/hispania.2020.009 
la compra de edificios que pasarían a ser de titularidad pública y, sobre todo, gastos ligados a la apariencia de los representantes del consistorio no pudo constituir asimismo un instrumento al servicio de unos pocos. Es justo en esta línea como la historiografía del arte había interpretado la mayoría de los retablos encargados para capillas de casas concejiles a partir de la década de 1440, considerados un objeto propagandístico de las respectivas corporaciones sin descartar una maniobra de legitimación del poder establecido en unos momentos de dificultades y tensión política y social ${ }^{81}$.

En cualquier caso, a la luz de los datos reunidos y que deberían ampliarse y precisarse mediante más estudios de caso, podría proponerse una hipótesis que nos remite sobre todo al terreno político y, más concretamente, al de la correlación de poderes que se articuló en el Principado de Cataluña a partir de finales del siglo XIV. Retomando una expresión de trabajos clásicos sobre la edilicia pública, todo indica que en las ciudades y villas del principado se produjo en este momento un proceso gradual de «petrificación» - «tesaurización» en el caso de los retablos, la indumentaria y el ornato en general - del capital simbólico o patrimonio inmaterial que habían ido acumulando las corporaciones municipales ${ }^{82}$. Y todo ello enmarcado, sin duda, en una operación más amplia de construcción de una identidad propia y emancipada de otros poderes, según apuntan estudios de autores como P. Verdés o F. Sabaté ${ }^{83}$.

El fenómeno, tal como se ha señalado, de alcance europeo y con la Península Itálica y Flandes como exponentes más claros, suponía culminar una primera gran etapa en la consolidación de las instituciones propias de las comunidades locales que la guerra y las exigencias fiscales habían acelerado. Gracias a ello, en el marco de estos nuevos escenarios y de una decoración y vestuario renovados, a la largo del siglo XV y en los siguientes, los ediles locales seguirán estableciendo negociaciones con el resto de instancias políticas, con la monarquía, por supuesto, pero también con otros señores jurisdiccionales o prelados. Sin embargo, lo harán desde una posición que, al menos en

${ }^{81}$ MOLINA 1999: 133-143. Sería, pues, coherente con los estudios existentes sobre las décadas centrales del siglo XV, cuando se multiplicaron los bandos en bastantes localidades y, al mismo tiempo, se detecta una creciente dialéctica entre la monarquía o las altas esferas de la administración regia y las autoridades municipales de las principales ciudades catalanas: FERNÀNDEZ TRABAL, 1999: 357-362. SABATÉ, 2009.

${ }^{82}$ Expresión presente, por ejemplo, en BOUCHERON, 1998: 407, retomando una línea de estudios con autores de procedencia diversa como R. S. López, J. P. Sosson o Richard A. Goldthwaite.

${ }^{83}$ VERDÉS, 2011. A propósito de la consolidación, fruto de distintas dinámicas, del gobierno municipal de Barcelona (entre otras grandes ciudades) como poder indiscutible dentro del conjunto de la corona a partir de las últimas décadas del siglo XIV, SABATÉ, 2017: 107-116. 
apariencia o como se pretendía subrayar, se había visto muy reforzada con respecto a la etapa anterior a 1350 .

\section{Biblogr afía}

Adroer Tasis, Anna Maria, «Barcelona: jardins medievals i renaixentistes», en Salvador Claramunt (coord.), El món urbà a la Corona d'Aragó del 1137 als decrets de Nova Planta: XVII Congrés d'Història de la Corona d'Aragó, Barcelona, Universitat de Barcelona, 2003, vol. II: 483-492.

Banks, Philip, «L'estructura urbana de Barcelona», en Jaume Sobrequés (dir.), Història de Barcelona, Barcelona, Ajuntament de Barcelona/Enciclopèdia Catalana, 1992, vol. 2: 25-71.

Barrio Barrio, Juan Antonio, "Que als dits ordenaments e capítols sien meses en memòria de scriptura». Modelos de identidad urbana en el reino de Valencia, siglos XIII-XV», Anales de la Universidad de Alicante. Historia medieval, 16 (Alicante, 2009-2010): 245-274.

Batlle Gallart, Carme, La crisis social y económica de Barcelona a mediados del siglo XIV, Barcelona, CSIC, 1973, 2 vols.

Batlle Gallart, Carme, «Esquema de l'evolució del municipi medieval a Catalunya», Estudis baleàrics, V/31 (Palma de Mallorca, 1988): 61-72.

Batlle Gallart, Carme, Ferrer Mallol, Maria Teresa, et al. (eds.), El «Llibre del Consell» de la ciutat de Barcelona. Segle XIV: les eleccions municipals, Barcelona, CSIC/IMF, 2007.

Batlle Prats, Lluís, «Inventarios municipales gerundenses del siglo XV», Annals de l'Institut d'Estudis Gironins, 6 (Gerona, 1951): 179-192.

Batlle Prats, Lluís, «La Casa del Concell de Gerona en 1498», Annals de l'Institut d'Estudis Gironins, 17 (Gerona, 1964-1965): 373-381.

Batlle Prats, Lluís, «La antigua capilla de San Miguel de la casa de la ciudad», Annals de l'Institut d'Estudis Gironins, 20 (Gerona, 1970): 317-355.

Bedos-Rezak, Brigitte Miriam, «Du modèle à l'image: les signes de l'identité urbaine au Moyen Âge», en Marc Boone, Élodie Lecuppre-Desjardin y Jean-Pierre Sosson (eds.), Le verbe, l'image et les représentations de la société urbaine au Moyen Âge, Anvers-Apeldoom, Garant, 2002: 189-205.

Bernaus Vidal, Magdalena, «La llotja de Barcelona», en Antoni Pladevall, L'art gòtic a Catalunya. Arquitectura III: Dels palaus a les masies, Barcelona, Enciclopèdia Catalana, 2003: 213-217.

Beseran Ramon, Pere, «Gòtic i neogòtic a la Casa de la Ciutat», Barcelona Quaderns d'Història, 8 (Barcelona, 2003): 273-299.

Beseran Ramon, Pere, «La casa de la Ciutat de Barcelona», en Antoni Pladevall (ed.), L'art gòtic a Catalunya. Arquitectura III: Dels palaus a les masies, Barcelona, Enciclopèdia Catalana, 2003: 183-188.

Bisson, Thomas N., «Pouvoir et consuls à Toulouse (1150-1205)», en Hélène Débax (ed.), Les sociétés méridionales à l'âge féodal (Espagne, Italie et sud de la France 
$X^{e}$-XIII s.) Hommage à Pierre Bonnassie, Toulouse, CNRS/Université Toulouse/ Le Mirail, 1999: 197-202.

Bolós, Jordi y Sànchez, Imma, «La ciutat de Lleida», en Antoni Pladevall (ed.), L'art gòtic a Catalunya. Arquitectura III: Dels palaus a les masies, Barcelona, Enciclopèdia Catalana, 2003: 59-62.

Bonachía Hernando, Juan A., «Obras públicas, fiscalidad y bien común en las ciudades de la Castilla bajomedieval», en José M. Monsalvo Antón (ed.), Sociedades urbanas y culturas politicas en la Baja Edad Media castellana, Salamanca, Ediciones Universidad, 2013: 17-48.

Bosom Isern, Sebastià y Vela Palomares, Susanna (eds.), Llibre de privilegis de la vila de Puigcerdà, Barelona, Fundació Noguera, 2007.

Boucheron, Pierre, Le pouvoir de bâtir. Urbanisme et politique édilitaire à Milan (XIV-XVe siècles), Rome, École Française de Rome, 1998.

Boucheron, Pierre y Chiffoleau, Jacques, Les palais dans la ville. Espaces urbains et lieux de la puissance publique dans la Mediterranée médiévale, Lyon, Presses Universitaires de Lyon, 2004.

Caille, Jacqueline, «Les traits médiévaux du visage urbain ( $\mathrm{V}^{\mathrm{e}}-\mathrm{XV} \mathrm{V}^{\mathrm{e}}$ siècles)», en Jacques Michaud y André Cabanis (dirs.), Histoire de Narbonne, Toulouse, Privat, 2004: 193-200.

Canal Roquet, Josep, et al., Atles d'Història Urbana de Girona, segles VI aC - XVI, Girona, Ajuntament de Girona, 2010.

Cantarellas Camps, Catalina y Tugores Truyol, Francesca, «A propòsit de l'església de Sant Andreu i de la capella de Sant Eloi a partir del segle XIV (Casa de la Universitat de Ciutat de Mallorca - Ajuntament de Palma)», Bolleti Societat Arqueològica Lul.liana, 70 (Palma de Mallorca, 2014): 117-139.

Carbonell Buades, Marià (dir.), El Palau de la Generalitat de Catalunya: art $i$ arquitectura, Barcelona, Generalitat de Catalunya, 2015, 2 vols.

Cateura Bennasser, Pau, «Obras públicas en tiempo de crisis: Mallorca, 1400-1450», Mayurqa, 23 (Palma de Mallorca, 1996): 31-42.

Cazes, Quitterie, «Toulouse au Moyen Âge: les pouvoirs dans la ville», en Patrick Boucheron y Jean-Philippe Genet (dirs.), Marquer la ville: Signes, traces, empreintes du pouvoir (XIIIe-XVIe siècles), París/Roma, Éditions de la Sorbonne, 2013: 341-366.

Chastang, Pierre, La ville, le gouvernement et l'écrit à Montpellier (XII ${ }^{e}-X I V^{e}$ siècle): Essai d'histoire sociale, París, Publications de la Sorbonne, 2013.

Chevalier, Bernard, «Les villes et leurs hôtels», en Alain Salamagne (ed.), Hôtels de ville: Architecture publique à la Renaissance, Tours, Presses universitaires François-Rabelais, 2015: 15-26.

Codina, Jaume y Sabí, Peris, «Ordinacions de Girona de l'any 1358», Annals de l'Institut d'Estudis Gironins, 28 (Gerona, 1985): 191-209.

Companys Farrerons, Isabel, Catàleg de la col-lecció de pergamins de l'Ajuntament de Tarragona dipositats a l'Arxiu Històric de Tarragona, Tarragona, Arxiu Històric, 2009.

Coomans, Thomas, «Belfries, cloth halls, hospitals and mendicant churches: A new urban architecture in the Low Countries around 1300», en Alexandra Gajewski y 
Zoë Opacic (eds.), The Year 1300 and the Creation of a New European Architecture, Turnhout, Brepols, 2007: 185-202.

Cortiella Òdena, Francesc, Una ciutat catalana a darreries de la baixa edat mitjana: Tarragona, Tarragona, Diputació de Tarragona, 1984.

Coy Cotonat, Agustín, Vilafranca del Penadés: su historia y monumentos, Barcelona, Imp. de Francisco J. Altés y Alabart, 1909.

Cruz Rodríguez, Joan, «El municipi igualadí medieval: una aproximació al seu funcionament (1282 - circa 1388)», Miscellanea Aqualatensia, 8 (Igualada, 1997): 19-58.

Cubeles Bonet, Albert, «L'evolució de les actuacions del Consell de Cent en matèria d'urbanisme al segle XIV», Barcelona Quaderns d'Història, 4 (Barcelona, 2001): 128-145.

Curto Homedes, Albert, «Origen i evolució de l'Arxiu de la Ciutat de Tortosa (segles XIV-XVII)», Lligall, 18 (Barcelona, 2001): 121-146.

Daileader, Philip, True Citizens: Violence, Memory and Identity in Medieval Perpignan, Leiden/Boston/Cologne, Brill, 2000.

Dalmases, Núria de, «Arquitectura gòtica civil», en Xavier Barral Altet (ed.), Art de Catalunya. Ars Cataloniae, 3: Urbanisme, arquitectura civil i industrial, Barcelona, L'Isard, 1997: 117-169.

Diacciati, Silvia y Tanzini, Lorenzo, «Uno spazio per il potere: palazzo pubblici nell'Italia comunale», en Silvia Diacciati y Lorenzo Tanzini (a cura de), Società e poteri nell'Italia medievale, Studi degli allievi per Jean-Claude Maire Vigueur, Roma, Viella, 2014: 59-80.

Diago Hernando, Máximo, «Haciendas municipales en el reino de Aragón durante el siglo XIV: El caso de Calatayud y su comunidad de aldeas», en Denis Menjot y Manuel Sánchez Martínez (eds.), Fiscalidad de Estado y fiscalidad municipal en los reinos hispánicos medievales, Madrid, Casa de Velázquez, 2006: 335-356.

Duran i Sanpere, Agustí, Barcelona i la seva història, Barcelona, Curial, 1972, 3 vols.

Español Bertran, Francesca, Els escenaris del rei. Art i monarquía a la Corona d'Aragó, Manresa, Angle, 2001.

Español Bertran, Francesca, El gòtic català, Manresa, Angle, 2002.

Farías Zurita, Víctor, El mas i la vila a la Catalunya medieval: Els fonaments d'una societat senyoralitzada, segles XI-XIV, Valencia, Publicacions de la Universitat de València, 2009.

Feliu Montfort, Gaspar, «La crisis catalana de la baja Edad Media: estado de la cuestión», Hispania, 64/2 (Madrid, 2004): 435-466.

Fernàndez Trabal, Josep, «De 'prohoms' a ciudadanos honrados: Aproximación al estudio de las elites urbanas de la sociedad catalana bajomedieval (s. XIV-XV)», Revista d'història medieval, 10 (Valencia, 1999): 331-370.

Furió Diego, Antoni, «Deuda pública e intereses privados. Finanzas y fiscalidad municipales en la Corona de Aragón», Edad Media. Revista de Historia, 2 (Valladolid, 1999): 35-79.

Furió Diego, Antoni, «La crisis de la Baja Edad Media: una revisión», en Las crisis a lo largo de la historia, Valladolid, Universidad de Valladolid, 2010: 13-45.

García Marsilla, Juan Vicente, «La moda no es capricho. Mensajes y funciones del vestido en la Edad Media», Vínculos de Historia, 6 (Ciudad Real, 2017): 71-88. 
Garganté Llanes, Maria, «Les cases consistorials a les comarques de Ponent, un ressò classicista en l'arquitectura civil catalana dels segles XVII i XVIII», Locus amoenus, 7 (Bellaterra, 2004): 237-253.

Gironella Delgà, Anna, «Fons documentals per a l'estudi de l'urbanisme a Girona en època medieval», Construir la ciutat (I), De Kerunta a la crisi baixmedieval, Conferències a l'Arxiu Municipal 8, Gerona, Ajuntament de Girona, 2013: 9-40.

Gironella Granés, Josep Maria, «Les residències castellonines dels comtes d'Empúries al segle XIV», Annals de l'Institut d'Estudis Empordanesos, 42 (Figueras, 2011): 251-261.

Gilli, Patrick y Salvatori, Enrica (dirs.), Les identités urbaines au Moyen Âge. Regards sur les villes du Midi français, Actes du colloque de Montpellier, 8-9 décembre 2011, Turnhout, Brepols, 2014.

Gouron, André, «Diffusion des consulats méridionaux et expansion du droit romain aux XIIe et XIIIe siècles», en André Gouron, La science du droit dans le Midi de la France au moyen âge, Londres, Variorum, 1984 (artículo original de 1963): 26-76.

Grohmann, Alberto, «L'edilizia e la città. Storiografia e fonti», en Simonetta Cavaciocchi (ed.), L'edilizia prima della Rivoluzione Industriale, secc. XIII-XVIII. Atti della Trentaseiesima Settimana di Studi, 26-30 aprile 2004, Florencia, Le Monnier-Istituto Internazionale di Storia Economica Francesco Datini, 2005: 109-136.

Guilleré, Christian, Girona al segle XIV, Gerona, Publicacions de l'Abadia de Montserrat, 1993-1994, 2 vols.

Hébert, Michel, «Les cartulaires municipaux de Provence à la fin du Moyen Âge. Jalons pour une enquête», Memini. Travaux et documents, 12 (Montreal, 2008): 43-83.

Igual Luis, David, «¿Crisis? ¿Qué crisis? El comercio internacional en los reinos hispánicos de la baja Edad Media», Edad Media. Revista de Historia, 8 (Valladolid, 2007): 203-223.

Jara Fuente, José Antonio (coord.), Ante su identidad. La ciudad hispánica en la Baja Edad Media, Cuenca, Universidad de Castilla-La Mancha, 2013.

Jean-Courret, Ézechiel, Lavaud, Sandrine, Petrowiste, Judicaël y Picot, Johan (dirs.), Le bazar de l'hôtel de ville: les attributs matériels du gouvernement urbain dans le Midi médiéval (XIIe-XVe siècle), Bordeaux, Ausonius, 2016.

Lafuente Gómez, Mario, «Agentes económicos y acción institucional: la reestructuración fiscal del concejo de Zaragoza entre las décadas de 1360 y 1380», en Mercedes Borrero, Juan Carrasco y Rafael G. Peinado (coords.), Agentes de los sistemas fiscales en Andalucía y los reinos hispánicos (siglos XIII-XVII): un modelo comparativo, Madrid, Instituto de Estudios Fiscales, 2014: 43-66.

Lampérez Romea, Vicente, Las ciudades españolas y su arquitectura municipal al finalizar la Edad Media, discurso leído por el Ilmo. Sr. D. Vicente Lamperez y Romea de su recepción pública, y contestación del Excmo. Sr. D. Enrique M. Rapullés y Vargas el día 20 de Mayo de 1917, Madrid, Real Academia de Bellas Artes de San Fernando, 1917.

Lecuppre-Desjardin, Élodie, «Des pouvoirs inscrits dans la pierre? Essai sur l'edilité urbaine dans les anciens Pays-Bas bourguignons au XVe siècle», Memini. Travaux et documents, 7 (Montreal, 2003): 7-35. 
Lecuppre-Desjardin, Élodie, La ville des cérémonies: essai sur la communication politique dans les anciens Pays-Bas bourguignons, Turnhout, Brepols, 2004.

Lecuppre-Desjardin, Élodie y Crouzet-Pavan, Elisabeth (eds.), Villes de Flandre et d'Italie (XIIIe-XVIe siècle). Les enseignements d'une comparaison, Turnhout, Brepols, 2008.

Lomba Serrano, Concepción, La casa consistorial en Aragón. Siglos XVI y XVII, Zaragoza, Diputación General de Aragón, 1989.

Martín Cea, Juan Carlos, «Las funciones sociales de la plaza pública en la Castilla del siglo XV», en José M. Monsalvo Antón (ed.), Sociedades urbanas y culturas politicas en la Baja Edad Media castellana, Salamanca, Ediciones Universidad, 2013: 143-164.

Menjot, Denis, «La ville et ses territoires dans l'Occident medieval: un système spatial. État de la question», en Beatriz Arízaga y Jesús Ángel Solórzano (eds.), La ciudad medieval y su influencia territorial, Logroño, Gobierno de la Rioja/Instituto de Estudios Riojanos, 2007: 451-492.

Molina Figueres, Joan, «La Virgen de los Consellers. Metáfora mariana e imagen de poder», Boletín del Museo e Instituto Camón Aznar, 77 (Zaragoza, 1999): 111-152.

Monnet, Pierre, «Pouvoir communal et communication politique dans les villes de l'Empire à la fi du Moyen Âge», Francia, 31/1 (París, 2004): 121-139.

Morelló Baget, Jordi, «Agli albori dell'istituzionalizzazione del microcredito sui cereali: l'insediamento delle Arcas di misericordia e dei pósitos municipali nel Basso Medioevo ispanico», en Ippolita Checcoli (ed.), I Monti frumentari e le forme di credito non monetarie fra Medioevo ed Età Contemporanea, Bologna, il Mulino, 2015: 391-425.

Munro, John H., «The anti-red shift - to the 'Dark Side': Colour changes in Flemish luxury woollens, 1300-1550», en Robin Netherton y Gale R. Owen-Corcker (eds.), Medieval Clothing and Textiles, Woodbridge, The Boydell Press, 2007, vol. 3: 55-95.

Narbona Vizcaíno, Rafael, «Algunas reflexiones sobre la participación vecinal en el gobierno de las ciudades de la Corona de Aragón (ss. XII-XV)», Res publica, 17 (Madrid, 2007): 113-150.

Narbona Vizcaíno, Rafael, La ciudad y la fiesta. Cultura de la representación en la sociedad medieval. Siglos XIII-XV, Madrid, Síntesis, 2017.

Navarro Espinach, Germán, «La industria de la construcción en los países de la Corona de Aragón (siglos XIII-XVI)», en Simonetta Cavaciocchi (ed.), L'edilizia prima della Rivoluzione Industriale, secc. XIII-XVIII. Atti della Trentaseisesima Settimana di Studi, 26-30 aprile 2004, Florencia, Le Monnier-Istituto Internazionale di Storia Economica Francesco Datini, 2005: 167-208.

Nieto Soria, José Manuel, Orígenes de la monarquía hispánica: propaganda y legitimación, ca. 1400-1520, Madrid, Dykinson, 1999.

Orti Gost, Pere, «El Consell de Cent durant 1'Edat Mitjana», Barcelona, Quaderns d'Història, 4 (Barcelona, 2001): 21-48.

Orti Gost, Pere, «Fiscalité et finances publiques dans les territoires de la couronne d'Aragon», Colloque L'impôt dans les villes de l'Occident méditerranéen (XIIIe-XVe siècles), París, Comité pour l'histoire économique et financière, 2005: 453468. 
Orti Gost, Pere, «Noves dades seriades per a noves hipòtesis sobre la crisi baixmedieval a Catalunya», en Jordi Morelló, Pere Orti y Pere Verdés (eds.), Renda feudal $i$ fiscalitat a la Catalunya baixmedieval. Estudis dedicats a Manuel Sánchez Martínez, Barcelona, IMF/CSIC, 2017: 463-484.

Orti Gost, Pere y Verdés Pijuan, Pere, «The Crisis of Public Finances in the Towns of Late Medieval Catalonia (1350-1500)», en Le crisi finanziarie: Gestione, implicazione sociali e conseguenze nell'età preindustriale, Atti Settimane di Studi e altri Convegni, Florencia, Firenze University Press, 2016: 199-221.

Otchakovsky-Laurens, François, «L'assemblée marseillaise au XIV siècle, quelle existence matérielle?», en Ézechiel Jean-Courret, Sandrine Lavaud, Judicaël Petrowiste y Johan Picot (dirs.), Le bazar de l'hôtel de ville: les attributs matériels du gouvernement urbain dans le Midi médiéval, Bordeaux, Ausonius, 2016: 215229.

Pastoureau, Michel, Rouge: histoire d'une couleur, París, Seuil, 2016.

Pladevall, Antoni (ed.), L'art gòtic a Catalunya. Arquitectura III: Dels palaus a les masies, Barcelona, Enciclopèdia Catalana, 2003.

Poisson, Olivier, «Les édifices du pouvoir civil du Moyen Âge à Perpignan: un rapide bilan patrimonial», La ciutat i els poders. La ville et les pouvoirs. Actes du colloque du huitième centenaire de la charte de Perpignan 23/25 octobre 1997, Perpignan, Institut Catalan de Recherche en Sciences Sociales/Presses Universitaires de Perpignan, 2000: 91-98.

Puig i Cadafalch, Josep et al., L'architecture gothique civile en Catalogne, París, Fondation Cambó/H. Laurens, 1935.

Puig Sanchis, Isidre, «Jaume Ferrer II», en Antoni Pladevall (dir.), L’Art Gòtic a Catalunya, Pintura 2: El corrent internacional, Barcelona, Enciclopèdia Catalana, 2005: 304-314

Puigferrat Oliva, Carles, «La casa de la Ciutat de Vic», en Antoni Pladevall (dir.), L'Art Gòtic a Catalunya, Arquitectura, 3: Dels palaus a les masies, Barcelona, Enciclopèdia Catalana, 2003: 189-190.

Pujol Canelles, Miquel, La construcció de la llotja de Castelló d'Empúries, Castelló d'Empúries, trabajo inédito depositado en el Archivo Municipal de Castelló d'Empúries, s. d.

Pujol Hamelink, Marcel, La vila de Roses (segles XIV-XVI), Roses, Brau, 1997.

Raufast Chico, Miguel, «¿Un mismo ceremonial para dos dinastías?: las entradas reales de Martín el Humano (1397) y Fernando I (1412) en Barcelona», En la España medieval, 30 (Madrid, 2007): 91-129.

Reixach Sala, Albert, Institucions locals i elits a la Catalunya baixmedieval (Girona, 1345-1445), Barcelona, Fundació Noguera, 2019, 2 vols.

Ribalta Haro, Jaume y Turull Rubinat, Max, Llibre de concells de la paeria (Març a setembre de 1344), Butlleti de dialectología nord-occidental, 3, Fondarella, Edicions del Butlletí, 1993.

Riera Sans, Jaume, Els poders públics i les sinagogues: segles XIII-XV, Gerona, Patronat Call, 2006.

Riu-Barrera, Eduard, «Les cases dels consells municipals i la Generalitat», en Antoni Pladevall, L'art gòtic a Catalunya. Arquitectura III: Dels palaus a les masies, Barcelona, Enciclopèdia Catalana, 2003: 179-182. 
Rodríguez López, Ana, «Spain», en Harry Kitsifopoulos (ed.), Agrarian Change and Crisis in Europe, 1200-1500, New York, Routledge, 2012: 167-203.

Sabaté Curull, Flocel, El territori de la Catalunya medieval: Percepció de l'espai $i$ divisió territorial al llarg de l'Edat Mitjana, Barcelona, Fundació Salvador Vives i Casajuana, 1997.

Sabaté Curull, Flocel, «Administración general de la Corona», en Eloísa Ramírez Vaquero, Pedro Andrés Porras Arboledas y Flocel Sabaté Curull, Historia de España, La época medieval: administración y gobierno, Barcelona, Istmo, 2003: 345-467.

Sabaté Curull, Flocel, «Oligarchies and social fractures in the cities of late medieval Catalonia», en María Asenjo González (ed.), Oligarchy and Patronage in Late Medieval Spanish Urban Society, Turnhout, Brepols, 2009: 1-27.

Sabaté Curull, Flocel, "Ciudad e identidad en la Cataluña bajomedieval», en José Antonio Jara Fuente (coord.), Ante su identidad: La ciudad hispànica en la Baja Edad Media, Cuenca, Ediciones de la Universidad de Castilla-La Mancha, 2013: 177-214.

Sabaté Curull, Flocel, «Barcelona: the building of a territorial and ideological capital», Viator, 18/1 (Los Ángeles, 2017): 107-118.

Sabaté Curull, Flocel, «La comuna idealitzada i rebutjada a la Catalunya baixmedieval», en Flocel Sabaté (ed.), Els espais de poder a la ciutat medieval, Lérida, Pagès, 2018: 123-154.

Salamagne, Alain, «Édifices publics et hôtels de ville: fin Moyen Âge - debut de l'Époque moderne», en Alain Salamagne (ed.), Hôtels de ville: Architecture publique à la Renaissance, Tours, Presses universitaires François-Rabelais, 2015: 27-59.

Salvadó Cabre, Nati, Buti Papiol, Salvador, Ruiz Quesada, Francesc et al., «Mare de Déu dels Consellers, de Lluís Dalmau: una nova tècnica per a una obra singular», Butlleti del Museu d'Art de Catalunya, 9 (Barcelona, 2008): 43-61.

Sánchez Martínez, Manuel, Furió Diego, Antoni y Sesma Muñoz, J. Ángel: «Old and New Forms of Taxation in the Crown of Aragon (13th-14th Centuries)», en Simonetta Cavaciocchi (ed.), La fiscalità nell'economia europea secc. XIII-XVIII, Atti della «Trentanovesima Settimana di Studi», 22-26 aprile 2007, Florencia, Firenze University Press, 2008, vol. I: 99-130.

Serra Desfilis, Amadeo, «El fasto del palacio inacabado. La Casa de la ciudad de Valencia en los sigos XIV y XV», en Historia de la ciudad III, Arquitectura y transformación urbana de la ciudad de Valencia, Valencia, Universitat de Valencia, 2004: 73-99.

Serra Desfilis, Amadeo, «Arquitectura y poder civil en las ciudades de la Corona de Aragón (siglos XIII-XV)», en Tina Sabater y Eduardo Carrero (eds.), La Ciutat de Mallorca $i$ els segles del gòtic, XXVIII Jornades d'Estudis Històrics Locals, Palma, 3-5 novembre, 2009, Palma de Mallorca, Institut d'Estudis Baleàrics, 2010: 57-78.

Stym-Popper, Sylvain, «L'architecture civile à Perpignan», Congrés archéologique de France, 112 Le Roussillon, París, Société française d'archéologie, 1954, vol. 112: 119-134.

Torras Serra, Marc (ed.), El Llibre Verd de Manresa (1218-1902), Barcelona, Fundació Noguera, 1996.

Hispania, 2020, vol. LXXX, n. ${ }^{\circ}$ 265, mayo-agosto, págs. 343-372, ISSN: 0018-2141, e-ISSN: 1988-8368 
Torras Serra, Marc, Els privilegis del «Llibre Verd» de Manresa, Manresa, Parcir, 1998.

Turull Rubinat, Max, «"Universitas, commune, consilium”: sur le rôle de la fiscalité dans la naissance et le développement du Conseil (Catalogne, XIIe-XIVe siècles)», en Bernard Durand y Laurent Mayali (eds.), Excerptiones iuris: Studies in Honor of André Gouron, Berkeley, The Robbins Collection, 2000: 637-677.

Turull Rubinat, Max y Verdés Pijuan, Pere, «Gobierno municipal y fiscalidad en Cataluña durante la baja edad media», Anuario de Historia del Derecho Español, 76 (Madrid, 2006): 507-530.

Velasco González, Alberto, «"Para que sus deliberaciones y consejos no vayan herrados sino acertados", Gonzalo de la Caballería y el retablo de la capilla del concejo de Zaragoza (1443)», Turiaso, 22 (Tarazona, 2014-2015): 295-340.

Verdés Pijuan, Pere, «Administrar les pecúnies e béns de la universitat». La politica fiscal $i$ les estratègies financeres d'un municipi català a la baixa Edat Mitjana (Cervera, 1387-1516), Barcelona, Universitat de Barcelona, tesis doctoral inédita, 2004.

Verdés Pijuan, Pere, «Car vuy en la Cort no s’i fa res sens diners. En torno a la negociación entre la villa de Cervera y el rey durante la baja Edad Media» en M. Teresa Ferrer i Mallol et al. (eds.), Negociar en la Edad Media, Barcelona, CSIC, 2005: 185-214.

Verdés Pijuan, Pere, «La ciudad en el espejo: hacienda municipal e identidad urbana en la Cataluña bajomedieval», Anales de la Universidad de Alicante. Historia Medieval, 16 (Alicante, 2009-10): 137-173.

Verdés Pijuan, Pere, «"Atès que la utilitat de la universitat deu precehir lo singular": Discurso fiscal e identidad política en Cervera durante el s. XV», Hispania, LXXI/238 (Madrid, 2011): 409-436.

Verdés Pijuan, Pere, «Car les talles són difícils de fer e pijors de exigir. A propósito del discurso fiscal en las ciudades catalanas durante la época bajomedieval», Studia Historica, Historia medieval, 30 (Salamanca, 2012): 129-153.

Verdés Pijuan, Pere, «L'evolució dels ingressos fiscals del municipi de Cervera (13311516): un indicador de la conjuntura econòmica?», en Pau Cateura y Lluís Tudela (ed.), La crisi baixmedieval a la Corona d'Aragó (1350-1450), Palma de Mallorca, Illa, 2019: 121-141.

Verdés Pijuan, Pere, «Los libros del racional de Manresa (1408-1412): la clave de un sistema financiero municipal», en Pere Orti y Pere Verdés (eds.), El sistema financiero a finales de la Edad Media: agentes, instrumentos y métodos, Valencia, Publicacions de la Universitat de València, 2020: 139-186.

Verdés Pijuan, Pere, «Le contrôle de la gestion financière des villes catalanes au bas Moyen Âge: la comptabilité du "racional"», en Armand Jamme (ed.), Le pouvoir de compter et décompter. Formes et logiques des comptabilités d'État entre XIIe et XVIe siècle, Roma, École française de Rome, en prensa.

Vidal Franquet, Jacobo, Les obres de la ciutat: l'activitat constructiva de la Universitat de Tortosa a la baixa edat mitjana, Barcelona, Publicacions de l'Abadia de Montserrat, 2008.

Watts, John, The Making of Polities: Europe, 1300-1500, Cambridge, Cambridge University Press, 2009. 
Webster, Jill R., Els menorets: the franciscans in the Realms of Aragon. From St.

Francis to the Black Death, Toronto, Pontifical Institute of Mediaeval Studies, 1993.

Recibido: 04/02/2019

Aceptado: 30/01/2020 